\title{
The role of psychological distance in value creation
}

\author{
Jonas Holmqvist $^{1}$, Duncan Guest ${ }^{2} \&$ Christian Grönroos $^{3}$
}

${ }^{1}$ Department of Marketing and Customer Relationships, BEM Bordeaux

School of Management, Talence, France

${ }^{2}$ Psychology Division, Nottingham Trent University, UK

${ }^{3}$ Department of Marketing, Hanken School of Economics, Helsinki, Finland 


\begin{abstract}
Purpose - The field of service research has devoted considerable attention to the customer's role as value creator, but there is a lack of research on understanding customers' psychological processes in value creation. This paper highlights the importance of psychological distance in value-creation processes. Psychological distance is the customer's perceived distance from service interactions in terms of spatial distance, temporal distance social distance and hypothetical distance. Critically, psychological distance influences cognitive processes and can influence how customers think and feel about the service interaction. An appreciation of psychological distance within service contexts can help managers to tailor the interaction in order to facilitate value creation.
\end{abstract}

Methodology/approach - In this conceptual paper, we build on psychology research and service research to develop seven propositions that explore how psychological distance can operate within service interactions and how this might influence value creation.

Findings - We divide the propositions into three sections. The first concerns how perceived psychological distance from the service interaction can act as a barrier to entering a service interaction. In particular, we consider the influence of social distance and spatial distance within the context of service interactions. The second section examines how psychological distance to the expected point of service use can influence how customers construe the service and the value creation. The third aspect addresses customer-specific characteristics that can impact on value creation by influencing perceived psychological distance toward the service.

Research implications - Existing research suggests that customers ultimately decide if value is created in the interaction. This paper proposes that perceived psychological distance influences customers' value creation by examining the service interaction from the customer perspective. We suggest that complex context-specific features of the service interaction can be understood by considering psychological distance from the service interaction and from the service itself and evaluating how this impacts on value-creation processes.

Practical implications - From a practical point of view, the paper helps managers to better understand how to manage the service interaction with customers by identifying psychological antecedents of customer value creation.

Originality/value - The paper introduces the notion of psychological distance into service research about value, proposing that the customer's role in creating value in interactions with the service provider is influenced by the psychological distance to the interaction and to the service offered in this interaction.

Paper type - Conceptual paper 


\section{Introduction}

Customer value is at the core of service research, and the last decade has seen the field of service marketing devote considerable attention to the role that customers play in valuecreation processes (Bendapudi and Leone, 2003; Grönroos, 2008; Vargo and Lusch, 2004; 2008). Understanding customer value is of particular importance for service management as all business activities are ultimately directed towards value (Sheth and Uslay, 2007) and the ability to generate customer value is a crucial competitive advantage for service providers (Babin and James, 2010). Despite this increased focus on the customer as a key player in value creation, customer value remains an elusive concept (Carù and Cova, 2003; Gummerus, 2013). Addressing this elusiveness, the Nordic school has treated services as idiosyncratic, contextual and experiential emphasizing how services need to be understood from the perspective of individual differences between customers (Helkkula, Kelleher and Pihlström, 2012). Addressing this view within the Nordic school, this paper builds on the value spheres of the service logic (Grönroos and Voima, 2013) to argue that psychological distance may play a part in better understanding customer value at an individual level.

During the service process, customers create value partly in interactions with service providers (Vargo and Lusch, 2004), and partly independently from the service provider (Grönroos, 2008). The interactive part of value creation takes place at the interface between the customer and the service provider (Grönroos and Voima, 2013), highlighting the need to understand how customers perceive these service interactions. In the interactions, the service provider can engage with the customer's value-creation processes to become co-creators of value (Vargo and Lusch, 2004; Grönroos, 2008). However, the successful managing of this process requires that the service provider understands the factors that help determine value from the customer's perspective (Karaba and Kjeldgaard, 2013).

Building on this understanding of the value-creation process, this paper aims to advance a service understanding of how psychological distance influences customers' value creation, where psychological distance refers to the customer's sense of closeness to the service interaction and to the service. The paper is positioned within the stream of service logic, mainly developed within the Nordic school of service management, as the service logic offers a management-level view of the service perspective on business (e.g. Grönroos, 2008; Grönroos and Voima, 2013). We propose that understanding customers' psychological processes is key to this management-level view of services. The theoretical foundation of the paper rests on two literature streams, service research and psychology research. We use the service literature to show how service research describes value creation and value perceptions, 
and further highlight a research gap consisting of a lack of concrete understanding of the psychological processes that influence how a service interaction is perceived by the customer (Dasu and Chase, 2011). To address this research gap we highlight one factor, psychological distance that may either hinder or help customers' value-creation processes.

Throughout the paper, we take the perspective that value is derived from the use of the service (Vargo and Lusch, 2004), that customers are always value creators (Grönroos 2008, 2011) and that service providers can become value co-creators by interacting with customers (Grönroos and Voima, 2013). Although service researchers have studied the notion of value creation in detail (Grönroos 2008; Payne, Storbacka and Frow, 2007; Vargo and Lusch, 2004, 2008), the field of service has paid less attention to the exact nature of the interactions between customers and service providers, and to how these interactions drive value creation (Dasu and Chase, 2013). Recently, service research has called attention to the need for a conceptualized understanding of customers' value perceptions (Grönroos, 2012; Gummerus, 2013; Peñaloza and Mish, 2011), highlighting that the customer's service experience is a complex phenomenon (Helkkula and Kelleher, 2010). Building on research within the field of psychology, we seek to address what characteristics of the service may facilitate value creation. We focus on the notion that psychological distance (the customer's sense of closeness) to the service interaction and to the service may influence the extent to which, and the way in which, value is created. To our knowledge, this notion of psychological distance has not been examined in the value creation literature.

In psychology, psychological distance refers to the perceived closeness to an experience. In recent years the concept of psychological distance and its effects on perception has gained much attention (see Trope and Liberman 2010 for a review). We use insights from this field to explore the effect of psychological distance on value creation in services. We explore three aspects of the service interaction, and use interaction to mean "situations in which the interacting parties are involved in each other's practices" (Grönroos and Voima, 2013 p.140). First we examine how the context of the interaction may influence psychological distance and how this context may impact on the customers' willingness to engage in an interaction to co-create value together with the service provider. We then focus on the psychological distance to the actual service itself and examine how this distance influences customer perceptions of the service and thus value creation. Finally, we take a step back and consider how customer characteristics might influence their perception of psychological distance and what this means for the value-creation process. 
Throughout this analysis we align these processes to the different spheres in which value creation takes place. Grönroos and Voima (2013) suggest three value creation spheres: the provider sphere, the joint sphere and the customer sphere. In the provider sphere, the service provider facilitates customers' value creation through providing resources for customers' use. In the joint sphere, customers and service providers co-create value through mutual interactions. Here customer and provider are co-producers of the service for the customer and thus co-creators of value. In the customer sphere, the customer creates value independently or in social interactions with friends or other persons (Grönroos and Voima, 2013). Bringing together current theoretical understandings of services and value creation with current psychological understanding of psychological distance based on construal level theory, we develop a set of seven propositions on the psychological processes relating to how psychological distance shapes customers' value creation.

\section{The concept of psychological distance}

Psychological distance refers to the perceived distance of an event (an experience that encompasses interactions and feelings) from a person's direct experience (Trope and Liberman, 2003). In a service interaction there are various types of distance; the interaction takes place in a physical setting (spatial distance), through interactions with the service providers (social distance) concerning services offered either now or in the future (temporal distance) that either have a high or low certainty of outcome and so seem more or less real (hypothetical distance). Consideration of these forms of distance is important in services, as psychological distance has an influence on cognition and thus on how services are construed.

The principle behind the notion of psychological distance is that various forms of distance (spatial, social, temporal and hypothetical) are egocentric; they are measured from the perspective of the individual (Trope and Liberman, 2003). Current psychological research suggests that all these distances are components of a single metric of egocentric distance: psychological distance (Trope and Liberman, 2010). This means that a feeling of spatial distance from someone generalizes to a feeling of social distance (and vice versa) because it influences our egocentric sense of psychological distance. Thus activating one type of distance automatically activates other dimensions of distance. For example, Stephan, Liberman and Trope (2010) found that increasing psychological distance by increasing spatial or temporal distance also increased social distance.

The principle of a single psychological distance that comprises aspects of social, spatial, temporal and hypothetical distance is critically important because increasing any of these 
egocentric distances is theorized to influence cognition similarly (see Trope, Liberman and Wakslak, 2007 for a review). Indeed, the relationship between psychological distance and cognition means that it is important to consider the effects of psychological distance in different settings, leading to the implications of psychological distance being examined in a wide range of fields (see Trope and Liberman 2010 for a review). As spatial, social, temporal and hypothetical distance are all features of service interactions, the automatic activation of a single psychological distance from these cues (Bar-Anan et al., 2007) may be an integral component of a service interaction. The importance of psychological distance rests upon the extent to which it influences the psychological processes that in turn influence the valuecreation process. In the next section, we review how psychological distance influences psychological processes before developing seven propositions to demonstrate why an appreciation of psychological distance is necessary in service contexts.

\section{Psychological distance and construal}

The construal level theory describes how psychological distance influences cognition (Trope and Liberman, 2003; 2010) and suggests that psychological distance influences the way in which we represent and construe information about an event or experience. It has long been recognized that we represent information at different levels of abstraction (Rosch, 1975, Vallacher and Wegner, 1987). For example, consider a contract for broadband service: we can construe this in terms of specific service features, such as the broadband speed, the usage allowance, the type of wireless router etc.; in terms of the product, enabling us to access the internet; or as a household service, similar to water, electricity/gas. As we move away from thinking about specific features of the service, to higher level conceptualizations (e.g. a household bill), the information associated with each level of construal becomes more abstract, for example, "something I get a monthly bill for" or "something connected with a house".

Construal level theory (Trope and Liberman, 2000, 2010; Trope et al., 2007) suggests that psychological distance is related to the level at which we construe information. An event that is represented at a low level of construal is highly contextualized and rich in detail (Bar-Anan, Liberman and Trope, 2006). This detail includes incidental or peripheral feature information that is not essential in order to understand the event; lower level construals are thus relatively unstructured. In contrast, when information is represented at a higher level of construal, the gist of the event is extracted, which results in the central features required for understanding being retained, but at a relatively abstract level in which the representation is decontextualized 
and all the peripheral and incidental features lost (Trope and Liberman, 2000, 2010). For example, a high level construal of university experience could be "studying at university in the UK" whereas a lower level construal could be "studying for a bachelor's degree in Politics and International Relations at Cambridge in 2000". By extracting the gist, the incidental and peripheral information is lost but the central information and its meaningfulness is retained.

Psychological distance and level of construal are highly related because we use knowledge differently at different levels of psychological distance (Trope and Liberman, 2003; 2010) When psychological distance is small, events impact on our direct experience because they are spatially and temporally close, they occur in the here and now. As such, representing information at a lower level of construal enables us to make use of the rich contextualized detail available. In contrast, when an event is spatially or temporally distant, this rich detail may not be available, and so representing the event in abstract gist-like terms is more useful (Trope et al., 2007). This link between psychological distance and construal level means that thinking at a higher level of construal primes a feeling of psychological distance (Bar-Anan et al., 2006; Trope and Liberman, 2003), with much work in the psychological literature validating these links (see Trope and Liberman, 2010 for a review). For example, manipulating whether people think about an event at a high level of construal (by asking people to think about an event in "why" terms which involves thinking more abstractly about the underlying reasons for completing a task) or a low level of construal (by asking people to think about an event in "how" terms which involves thinking about the necessary contextual details to perform the task) can influence how far in the future people judge the event to be (Liberman, Trope, Macrae, and Sherman, 2007). Importantly, changing the level at which an event is construed can influence perceived psychological distance from the event but the reverse is also true. Changing psychological distance from an event can thus also influence how it is construed. For example, Liberman, Sagristano, and Trope (2002) asked participants to imagine an event occurring in the near or far future. The participants then grouped a set of items that related to the event into as many categories as possible. Participants in the far future condition grouped items into fewer categories, suggesting that they thought in more abstract terms about the items and how these were related.

Adapting this understanding of psychological distance to services, we posit that psychological distance is an important concept for service research because it offers theoretical insight into how the context in which the service takes place can influence the way in which customers construe the service. The following section outlines how we see psychological distance operating within service settings. 


\section{The importance of psychological distance in service contexts}

Psychological distance consists of different forms of customer-centric distance, spatial, social, temporal and hypothetical and thus the relation between psychological distance and construal offers a unifying framework within which to understand how these seemingly disparate forms of distance influence how customers perceive and interact within the service setting. Holbrook (2005) notes that consumer value is an interactive, relativistic preference and experience. Value is relativistic because it differs between individuals and the situation in which an evaluation occurs. Examining psychological distance in services therefore offers an important framework within which to explore how different service settings and different service experiences influence value perceptions.

Service research recognizes that value in services arises from an interactive process (Grönroos, 2008; Grönroos and Voima 2013; Vargo and Lusch, 2004). In social psychology and marketing, Higgins $(2000,2006)$ has also suggested that value derives not just from target specific characteristics (e.g., the service) but also from the process, namely the force of the motivation in seeking that value. One of the central factors determining this motivation is the strength of the engagement with the process, that is, the extent to which one is fully absorbed in the process (Higgins and Scholer, 2009). In turn engagement strength is determined in part by how well customers align their orientation toward the goal that guides them with the strategic process used to attain this goal. When this regulatory fit occurs, this provides greater engagement and motivation intensity, increasing value. In other words, aligning the process with the customer's mind set (their goal-orientation) could increase value. This view of engagement and its relation to value has been incorporated into notions of customer engagement within the service literature (Brodie et al, 2011). In particular, it serves to highlight the importance of considering psychological distance in service settings. If an appreciation of psychological distance can be used to facilitate a service interaction in a way that fits with a customer's level of construal and their expectations about distance, it can increase engagement in the process and add value (Lee, Keller and Sternthal, 2010).

For service providers it is imperative to understand what customers value now and what they will value in the future (Woodruff, 1997). One important aspect of this involves understanding how customers represent, that is construe, information about a service and considering how information can be aligned with this construal. In recognition of this, research in marketing and management has examined the importance of psychological distance in different settings (see Dhar and Kim, 2007 for a review) including designing 
service guarantees (Jin and He, 2012) and responding to service failure (Lii, Chien, Pant and Lee, 2013).

Whilst the notion of psychological distance has received increased attention in marketing more generally (e.g., Jin and He, 2012; Miao and Mattila, 2013), the relevance of psychological distance to the interactive nature of services has not been explored. Services involve an interaction that takes place between people in a physical setting and concern events taking place in a particular time frame (Surprenant and Solomon 1987). Within the field of service research, a great deal of emphasis is placed on the notion that value arises through this interaction (Grönroos 2011, Grönroos and Voima, 2013; Vargo and Lusch, 2004), highlighting the importance of the context within which the service interaction operates (Holbrook, 2005). The concept of psychological distance is therefore useful as it offers a conceptual mechanism for understanding the complex context in which the interaction takes place by unifying different types of distance under a single psychological distance.

We suggest three roles of psychological distance in services. First, psychological distance can provide a barrier to customer willingness to engage in a service interaction and to interact with the service provider (Grönroos and Voima, 2013). In the service logic, one role of the service provider is to facilitate customers' value creation in the provider sphere (Grönroos, 2011; Grönroos and Voima, 2013) and this might be achieved by reducing the barrier created by psychological distance. Second, psychological distance between the customer and provider can be altered during the service interaction. This may help facilitate value co-creation through fostering greater connectedness between individuals within the service interaction (Kolb, 2008). Third, service interactions revolve around a service that often is yet to be fully used. This means that the customer has to create a construal of the service being offered. The perceived psychological distance of the customer from the service will therefore influence how customers construe the interaction. To facilitate value creation, the service provider needs to frame the service in a way that is aligned with how customers construe the service being offered, which we suggest is dependent on psychological distance.

The ways through which psychological distance may influence value can be conceptualized as taking place in different value spheres (Grönroos and Voima, 2013). The provider can act within the provider sphere to reduce psychological distance prior to, or during the service interaction to prevent psychological distance being a barrier to value creation. In the joint sphere the customer and service provider interact to co-create value. Here, the service provider facilitates value creation by reducing psychological distance and/or framing the service at the appropriate customer construal level. This can only take place in the 
service interaction within which the service provider can respond to the customer and the situation. In the customer sphere, individual characteristics influence how psychologically distant the customer feels from the service. This psychological distance will influence how customers approach and construe the service interaction, influencing their value creation processes. Post resource exchange customers can reflect on the service and whether their construal of the service and their expected psychological distance to it were aligned, influencing the value customers create independently in the customer sphere.

In sum, combining psychological distance with a service perspective allows service research to go beyond current knowledge of the service interaction and gain an improved insight into how customers' perceptions influence the value-creation process. As a relatively new and important theory within the psychology literature (Trope and Liberman, 2010), the notion of psychological distance is an important factor to consider in service interactions as it can help service research to reduce the elusiveness of customer value perceptions highlighted by Gummerus (2013) and Karababa and Kjeldgaard (2013). Based on this adaption of psychological distance to the service logic, we propose seven propositions about how psychological distance influences customer value.

\section{Psychological distance and its impact on value creation}

From the service provider's point of view, it is imperative that the service provides the customer with value, as being able to facilitate customers' value creation is one of the most important aspects for companies' long-term success (Babin and James, 2010). Importantly, the customer plays an important participative role in the service by interacting with the service provider (Bitner et al., 1997; Grönroos, 1978; Lovelock, 1983; Zeithaml, Berry, and Parasuraman, 1996). In some service contexts the role of the customer becomes even more crucial to the service outcome, as both the customer and the service provider depend on each other's competences (Nordin and Kowalkowski, 2010), underlining the importance of a close and mutual interaction in the joint value sphere (Grönroos and Voima, 2013). We propose that psychological distance may determine the extent to which a customer will be interested in engaging in a service interaction. Before entering into the service interaction, customers often consider the future interaction, and in so doing automatically assess psychological distance (Bar-Anan et al., 2007). For example, the interaction will have a spatial distance component (face to face versus a phone call) and a social distance component (customer familiarity with the service provider). If the psychological distance is large, we propose that the customer will be less willing to enter into the interaction due to two factors. First, large spatial and social 
distance prime greater temporal distance (Stephan, et al., 2010), leading to an association with the interaction taking place further in the future. Second, these psychological distances also influence the subjective probability of an event occurring (hypothetical distance). Events that definitely will happen feel psychologically closer, because they are more likely to be a part of our direct experience (Wakslak, Trope, Liberman, and Alony, 2006; Wakslak and Trope, 2009). Thus greater psychological distance is associated with a lower probability of an event occurring and a less certain outcome, making it seem riskier. This is of particular importance in the context of service research, as the intangible nature of services (see Zeithaml and Bitner, 2000) also leads customers to connect services with higher risk (Laroche et al., 2004). Each of these factors will decrease the perceived value to be gained from entering the service interaction. Reducing psychological distance to the service interaction will make customers more likely to believe that the service interaction will yield a tangible outcome and so enter into a service interaction which is a prerequisite of co-creating value in the joint value sphere (Grönroos and Voima, 2013).

\section{Proposition 1. Reducing psychological distance between customers and the service provider will increase the customers' expectation of a tangible outcome from the service, increasing customer willingness to enter into an interaction with the service provider}

In addition to influencing how customers perceive the tangibility of the service outcome, feeling psychologically distant from another can decrease willingness to interact with that person (see Sousa and Bradley, 2006). Thus psychological distance will influence the willingness to engage with the service provide and co-create value. Two forms of distance to the service provider are particularly important, social and spatial distance, and these represent two distinct barriers that service providers may wish to address (Citera et al., 2005; Henderson et al., 2006; Smith and Trope, 2006; Zhao and Xie, 2011). Social distance may arise from individual differences, such as gender, age or culture. Language use can also create distance, with more polite and formal language increasing psychological distance (Stephan et al., 2010). Recent service research also identifies how language use influences customers' reactions to the service provider (Van Vaerenbergh and Holmqvist, 2013) and their perceptions of the service (Holmqvist and Grönroos, 2012), with customers reacting more positively when addressed in their own language. Language use therefore offers a key way in which psychological distance between the customer and service provider can be minimized. 
In terms of spatial distance, physical components of the setting may influence psychological distance (e.g. a counter between the customer and service provider increases psychological distance). Although services have traditionally been seen as dyadic interactions in which the customer and the service personnel interact in person (Surprenant and Solomon, 1987) the development of the Internet has partly changed this situation, as interactions between customers and service providers now often take place without any face-to-face interaction (Grönroos et al., 2000). Moving from face to face interaction to virtual interactions increases psychological distance. Moreover, a virtual interaction can now take place between customers and service providers anywhere in the world. The geographical location of the service provider relative to the customer will also influence perceived psychological distance. Crucially, perceptions of distance to another individual influences the perceptions of that persons' personality (Rim, Uleman and Trope, 2009), how written material affiliated to that person is interpreted (Henderson et al, 2006) as well as how the interaction is represented and recalled (Fujita et al, 2006). For example, Fujita et al (2006) show that participants interpret an interaction with others more abstractly when they think it occurs in a more spatially distant place. Spatial distance from a service interaction may thus make a potential service interaction seem less concrete, may influence how the service provider is perceived and may create social distance. Citera et al. (2005) show that increasing psychological distance by moving from face to face interactions to virtual online interactions has a negative impact on the perceived credibility of the person with whom the customer interacts.

Both social distance and spatial distance may therefore create barriers to value creation because they will negatively influence how customers construe the service provider, for example, increased distance may further decrease the service provider's credibility in the eyes of the customer. This will reduce the customer's willingness to become part of the value cocreation process by engaging with the service provider.

\section{Proposition 2. Reducing spatial or social distance between customers and service providers will create a more positive impression of the service provider, increasing customer willingness to enter the interaction to co-create value in the joint value sphere.}

Propositions 1 and 2 both focus on how psychological distance can act as a barrier to entering a service interaction either due to the expected outcome of that interaction (Proposition 1) or due to how the service provider is perceived (Proposition 2). Both of these can occur before 
entering the interaction (pre-exchange of resources) and thus reflect potential value created in the provider sphere. However, Proposition 2 also has resonance with what may occur within an interaction as the service provider responds to the customer. For example, a key moderator of the effectiveness of service systems is social distance (Breidbach et al, 2013). Breidbach et al (2013) examined the role of technology enablement in co-creating value and suggested that the role of Information and Communication Technology (ICT) in co-creating value is dependent upon the level of social connectivity between the individuals using it. Social connectivity describes the strength of the social ties within a system that are required for successful exchange of resources. Lower social connectivity implies reduced social ties and is equivalent to greater social distance between individuals. Value co-creation becomes more challenging when there are lower levels of social connectivity, and thus greater psychological distance within the service system. Moreover, smaller group configurations yield better social connectivity due to the reduced social distance between the group members, and this leads to greater use of richer forms of communication (telephone rather than email), facilitating cocreated value.

Reducing psychological distance between individuals is therefore important, even in service systems that are more technological, such as technology enabled service encounters (Makarem, Mudambi and Podoshen, 2009) or e-services in which increasing social presence (and thus reducing social distance) is important (Cyr et al, 2007). More broadly, Kolb (2008) suggests that the metaphor of connectivity is central to understanding organizational behavior as a whole. Here connectivity implies social interactions as well as geo-physical (e.g. space, time and location) and technological interactions. From the egocentric standpoint of an individual within a service system (e.g., the consumer) psychological distance clearly relates to the notion of, and could be an antecedent of, social connectivity. Reducing psychological distance, be this social (who is interacting and how), spatial (where the interactions take place), temporal (when interactions will take place) or hypothetical distance (will the interactions take place), might therefore increase social connectivity in service interactions, making customers and service providers more willing to engage with each other during cocreation of value.

Proposition 3. Reduced psychological distance increases social connectivity and thus the willingness of customers and service providers to interact with each other during value co-creation processes in the joint value sphere. 
Proposition 3 builds upon evidence in the psychology literature to suggest how lower psychological distance benefits customers' value co-creation with the service provider in the joint value sphere. We propose, however, that these general preferences can be moderated. One moderator relates to the aforementioned regulatory fit (Higgins, 2006). Perceived value from a process can be influenced by how a customer engages with that process and whether this fits their motivational orientation toward the value promise (Higgins and Scholer, 2009). In approaching their goal, customers are individuals who might have particular, and individual, expectations about whether psychological distance is positive or negative. An example of this is when considering the authority of the service provider. In most instances, people will perceive more value in a service when interacting with someone who is familiar or similar to them (low social distance). However, in some services, customers might seek an authoritative figure (e.g., visiting a doctor or bank manager) as complete trust in the decision of the service provider is required (see Alford and Sherrel, 1996). Thus in these instances, larger social distance might be preferable because it maps onto consumer expectations about the process (needing guidance from authority). Thus, whilst propositions 1-3 hold true in the main, an important moderator is the extent to which the customers' experienced psychological distance fits with the psychological distance they expected. Aligning these could lead to a greater willingness to engage with the service provider in the joint value sphere.

\section{Proposition 4. Aligning expected and perceived psychological distance to service providers will increase customer willingness to interact with the service provider, facilitating value co-creation in the joint value sphere.}

\section{Psychological distance from the service}

When assessing a service, customers think about when and how they will use it, and thus about the potential value in use. Some customers may focus on more contextual details of the service, including more secondary and peripheral features while other customers may focus on more central aspects of the service (Liberman et al., 2007) and more about why it will yield potential value-in-use. Importantly, the level of construal will be influenced by perceptions of when the service will be used, with larger temporal distance being related to more abstract levels of construal. Findings from the fields of psychology and marketing suggest that it is important to align the context of the decision with the appropriate level of 
construal (Giacomantonio et al., 2010; Nenkov, 2012, Trope and Liberman, 2010). For example, customers tend to prefer a wider selection of choices in the here and now, but prefer a smaller range of choice when talking about future decisions (Goodman and Malkoc, 2012). This is because greater psychological distance leads customers to represent the choices at a higher construal level which is more abstract and makes the available options seem more substitutable.

Level of construal will also be influenced by hypothetical distance to the potential value in use. That is, the extent to which the value in use appears likely. In services value is created in a wide range of social, mental or physical contexts (Grönroos and Voima, 2013). An important aspect of the mental context is the role of imagined experiences ( $\mathrm{Ng}$, Nudurupati and Tasker, 2010, Grönroos and Voima, 2013) and fantasised experiences (Holbrook and Hirschman, 1982). By its nature, fantasising is involvement in unrealistic fantastical thought. Thus the more fantastical a customers' imagination of the service, the greater the hypothetical distance toward it (the likelihood of gaining the imagined value-in-use) in comparison to a more realistic imagined scenario.

Together, temporal distance and hypothetical distance toward value in use will influence how the service is construed. Crucially, a small or great psychological distance will not necessarily increase or decrease value creation, rather it will influence how customers perceive the service

It is critical then to evaluate how customers are construing the service. Are they construing the service at a higher more abstract level, or at a lower more concrete level? In interactions in which one party is advising the other, there can often be differences in the manner in which a choice is construed, with the adviser often representing the choice at a higher level of construal (Danziger, Montel and Barkan, 2012). It is important that the service provider recognizes the customer's level of construal and facilitates value creation through actively seeking alignment between the framing of the service and customers' construal level. Assessing the customers' psychological distance to the service can help identify the most appropriate level of construal with which to frame the service. In this sense, service providers can act in the provider sphere to facilitate the potential for value-in-use (Grönroos and Voima, 2013). Moreover, successfully determining the level of customer construal and adapting to this level enables the service provider and customer to better co-create value in the joint sphere. Whilst recent marketing research has investigated how different types of choices are best aligned with particular psychological distance and construal levels (Jin and He, 2012; Miao and Matilla, 2014; Zhao and Xie, 2011), we extend this thinking by suggesting that in a 
service interaction, it is necessary for the service provider to consider the psychological distance of the customer to the service (social, spatial, temporal and hypothetical distance). Service providers can do this through evaluating the spatial settings in which the service interactions occur, evaluating the similarity between typical customers and service providers, ascertaining from the customer when they will be using the service and the extent to which they are fantasising about the service.

Using this information to align description of the service in line with the customer's construal should facilitate value co-creation. We outline the general idea in Proposition 5, before providing more specific details in relation to important aspects of the service context in Proposition 6.

\section{Proposition 5. Framing the service in line with the customers' level of construal can help increase perceived value-in-use.}

Importantly, in a service interaction, the service provider can attempt to modulate the perceived point of value-in-use by talking hypothetically about the value gained tomorrow, or in a few months' time etc. Why might this be appropriate? Evidence suggests that certain decisions become more or less difficult for the customer when framed in terms of temporally close or distant terms. Crucially, it depends upon the characteristics of the decision. Nenkov (2012) shows that framing the decision in psychologically distant terms (e.g., the future) is beneficial at the start of the decision-making process where customers weigh up the pros and cons of pursuing a goal. In contrast, if in a post-decisional stage in which a goal has been decided upon but not the implementation, framing the decision in psychologically close terms (e.g., the present) is beneficial. Similarly, increasing psychological distance can reduce perceived task complexity (Thomas and Tsal, 2011) and increasing psychological distance can also increase a focus on the purpose of the choice rather than the specifics of how to reach that choice (Fujita et al, 2006). In general then, if the service interaction is about a complex service in which assessing value-in-use is demanding, then framing the service in terms of greater psychological distance (e.g., further into the future) could facilitate value co-creation in the joint sphere.

Proposition 6. Framing the service in psychologically distant terms can increase perceived value-in-use in complex service interactions. 


\section{The importance of customer characteristics}

In the propositions above, psychological distance is considered in relation to the contextual aspects of the service interaction. In the case of social distance, some of these contextual aspects depend on the characteristics of the customer and how they differ from the service provider (age, gender, culture and language use). The influence of these individual characteristics occurs throughout the value creation process as value emerges from considerations of past, present and future experiences (Helkkula et al. 2012). Importantly, part of this value creation occurs in the customer sphere, in which the customer interacts with resources provided by the service provider, whether physical, virtual, mental, or imaginary (Grönroos and Voima, 2013). Prior to the resource exchange, value in the customer sphere may be derived from the customer's perceptions of the value-in-use of the service and expectations about the service. Such expectations are subject to individual differences and influence how customers' approach the service. In the joint sphere, individual customer characteristics (e.g., those that influence social distance) influence the extent to which customers engage in value co-creation. Post resource exchange, value is created in the customer sphere when individuals reflect on the service experience, whether it was aligned with their expectations, and the extent to which the desired outcome has been realized. Although taking part in the customer sphere, the realization of this value is influenced by the value co-creation interactions in the joint value sphere. Again, individual differences will influence the extent to which a customer reflects on the service experience. Although a thorough review of the effects of individual differences on psychological distance and value creation is beyond the scope of this article, we provide an example of an individual characteristic that influence psychological distance and construal level in the customer sphere.

Individuals differ in the extent to which they have an emotional response to the service (an observable behavioral response that can be verbal and/or non-verbal). It is well established that services can be emotional experiences (Dasu and Chase, 2013) and that a customer's emotion is involved in the value creation process (Holbrook, 2005; Payne, Storbacka \& Frow, 2008). Emotion may occur in anticipation of a service, in response to the service, or in reflection of the service. Examples of services that some (but not all) customers may respond emotionally to include buying one's first car or going to a restaurant for a first date. In terms of psychological distance, the greater the emotional response to an event, the closer one feels to it (Van Boven et al, 2010). Not only does emotional intensity influence psychological distance, but the relationship is reciprocal (Davis, Gross and Oschsner, 2011; Thomas and Tsai, 2011). Thus decreasing psychological distance from a service can increase the emotional 
response associated with it. It is therefore crucial to consider the customers emotional response to the service and to use this aspect to reinforce the appropriate level of psychological distance. Again, the focus is on the service provider being sensitive to the customer's level of emotion. If the customer sees the service as an emotional and psychologically close experience (Van Boven et al, 2010) then the value-in-use of the service is best framed at a lower level of construal (Fujita et al, 2006; Liberman et al, 2007; Trope and Liberman, 2000), focusing on the context, the use of the service and a range of service features.

\section{Proposition 7. Emotional service experiences reduce psychological distance and so are best framed at a lower level of construal.}

Post resource exchange customers will reflect on the service and the service interaction. If the customer's construal of the service and psychological distance to it have been successfully aligned in the joint sphere, then reflecting on the service and service interaction will create value. Moreover, re-imagining the service outcomes will make the service experience seem more psychologically close. Individual differences will influence the extent to which an individual engages in this reflection. In personality psychology, there is a clear distinction between the traits of reflection (curiosity or epistemic interest in experiences involving the self) and rumination (thinking about threats, losses or injustices of experiences relating to the self) (Trapnell and Campbell, 1999). Similarly, personality traits such as extroversion may influence the extent to which an individual discusses a service experience with others (Grönroos and Voima, 2013).

\section{Discussion and Conclusion}

Managers and services researchers agree on the importance of understanding customers' value-creation processes, but the complexity of service processes (Helkkula and Kelleher, 2010) and the elusiveness of value (Carù and Cova, 2003) contribute to render this understanding a challenge for service research. From a managerial perspective, this means that psychological distance could make customers less willing to interact with the company, less interested in co-creating value during the interaction and less likely to appreciate the value after the interaction. All of these situations represent real problems for service providers, but the reasons behind these problems may often go undetected. We argue that understanding psychological distance relative to the three spheres of value creation (Grönroos 
and Voima, 2013) could help service researchers appreciate the role psychological processes play in service interactions and better understand the potential problems that psychological distance may cause.

The paper offers two main contributions to the field of service research. The first is to introduce the concept of psychological distance as a means for service researchers to extend current knowledge about customers' value perceptions, and the different ways in which the intricacies of an interaction might influence value creation. We believe that the concept of psychological distance is relevant to service research, because a sense of closeness in some form on the part of the customer is inherent to every interaction. We suggest that this perceived closeness of the interaction relates directly to the possible value creation, because it influences customer perceptions of the value that could be gained from entering an interaction and the willingness to engage in the interaction itself. We further acknowledge the importance of customer characteristics such as age, gender, culture and language use, as they all can influence the perceived closeness of the service interaction.

The second contribution is in distinguishing between psychological distance to the actual interaction, psychological distance within the interaction, and psychological distance to the service being offered. This distinction enables an analysis of the function of psychological distance in the different value spheres. In the provider sphere, we posit that the ways in which the company communicates and designs its services can influence customers' perceived distance to the service prior to the resource exchange. Increasing perceived distance risks making the service outcome seem less certain and the service personnel seem less reliable in the eyes of the customer even before the actual service encounter, thereby reducing customer willingness to enter into a service interaction. In the joint value sphere where customers and service providers co-create value, we propose that psychological distance could influence both how willingly and how well customers interact with the service provider, affecting the co-creation interaction. In the customer sphere, individual characteristics influence how psychologically distant the customer feels from the service and thus how the service interaction is construed. Individual characteristics also influence the extent to which customers reflect on the service experience post resource exchange and whether their construal of the service and their psychological distance to it were aligned. This will influence the extent to which value is created in the customer sphere.

This analysis poses a challenge for service research as it demonstrates the different ways in which customer perceived value is at risk due to difficulties arising from facets of psychological distance. 


\section{Table 1 about here}

\section{Research challenges, future research and limitations}

This paper approaches psychological distance in value creation from the service logic perspective of the Nordic school to pose a number of challenges to the current service research. Adapting the concept of psychological distance to the discussions about customer value, the paper challenges the current service research by suggesting that the service field needs to understand how customers' perceptions and construals influence value. Even though most researchers agree that customers ultimately decide if value is created or not, extant research on value remain largely focused on objective criteria, trying to describe what objectively constitutes customer value. Our paper challenges this view, as we agree with Helkkula et al. (2012) that value is individual. This does not mean that we cannot make predictions and assumptions about what objective aspects will contribute to customer value, but our propositions posit that there are numerous aspects, grouped together under the notion of psychological distance, that service researchers need to take into account in order to better understand how customers perceive value. In seven propositions, we outline how the notion of psychological distance can add to our understanding of value creation in services. Future empirical data is needed to test and validate the propositions and further clarify how psychological distance influences customers' value creation. We also believe that examining how maintaining psychological closeness to the service experience through reflecting on the experience influences customer value creation in the customer sphere would be a fruitful avenue for future research. Building on our propositions, we develop fifteen potential research questions that could help service research shed additional light on how psychological distance influences customer value. We outline these research questions in Table 1.

In addition to presenting challenges to the current service research, our paper also presents a number of limitations. Building on the service logic, our propositions tend to address value creation in dyadic processes between customers and providers. A limitation, and a possibility for future research, would be to further investigate psychological distance in interactions amongst actors in service systems. Building on the notion of value spheres in the Nordic School (Grönroos and Voima, 2013), our main interest is the interaction between customers and service providers. Taking a more in-depth service science approach to look at the entire configuration of people, technology and value propositions (see Maglio and Spohrer, 2008) would be a logical next step, allowing researchers to apply psychological distance to the entire 
service system and its role in the configurations of both the external and the internal systems (Maglio and Spohrer, 2008; Spohrer, Maglio, Bailey, and Gruhl, 2007).

The purpose of this paper is to bring together two distinct research fields (value creation and psychological distance) in order to offer a new direction for research. As such, some of the ideas explored simply touch the surface and require fuller treatment. For example, whilst we have highlighted the role of individual characteristics in influencing value creation in the joint sphere and the customer sphere a much more extensive review of how individual characteristics influence psychological distance and value creation is required. Other issues we have not touched upon but remain important avenues for future research include examining possible cultural differences in how psychological distance influences value creation. In some cultures, low psychological distance is seen as preferable while other cultures are more hierarchical. It would seem likely that there are situations in which lower psychological distance could be beneficial for value creation in some cultures, while being detrimental for value creation in other cultures.

While all propositions have support in the psychology literature, future empirical data is needed in order to understand the role of psychological distance for customers and to understand the extent to which psychological distance influences value creation. Such research will have to find reliable ways of measuring value created in services. As services are personality-intensive (Normann, 2000) and value is a complex phenomenon composed of several elements (see Helkkula and Kelleher 2010) it would be relevant to test how psychological distance applies to different aspects of value creation in services. For example, it is possible that psychological distance influences only some aspects of value, or that the different forms of distance outlined in the propositions influence different aspects of value.

\section{Managerial challenges}

For managers, the propositions in this paper pose a number of challenges and possibilities in terms of developing a successful service strategy. The psychological distance that consumers perceive to the service provider and the actual service encounter cannot be seen as an inherently beneficial or detrimental aspect. Propositions one and four illustrate this point. Proposition one implies that managers need to reduce psychological distance in order to increase customer willingness to take part in value co-creation in the joint value sphere. However, it is not always the case, as indicated by the importance of the service context as outlined in proposition four, whereby increased psychological distance may facilitate value co-creation in the joint value sphere. This contrast is explained by the type of service; we 
propose that reduced psychological distance is beneficial in most cases, but Proposition four shows that in services where perceived authority is important, increasing social distance may be preferable. Managers need to keep this distinction in mind and align psychological distance with the kind of service they offer. As such, managers should consider both the service context and the customer's psychological distance at different stages of the service interaction. What spatial, social, temporal and hypothetical features of their typical service experience may prevent customers entering the service interaction? What levels of psychological distance exist between individuals in the service interaction? How are customers construing the service? Do consumers see the service interaction as an emotional event? How do individual customer characteristics influence psychological distance in the service? Asking these questions will give manager insight into the customers' perspective of the service, which is essential in order to co-create value (Dasu and Chase, 2013).

\section{Conclusions}

The propositions in this paper address the call of Grönroos (2012), Gummerus (2013) and Peñaloza and Mish (2011) for the need to better understand value. Addressing psychological distance in value creation, the paper draws attention to the role of the individual. We identify customer characteristics as a crucial aspect in order to understand the processes that determine value creation. Services are inherently personality-intensive, depending on the individuals involved (Normann, 2000) and each customer approaches the service interaction with contextual and idiosyncratic individual differences (Helkkula et al., 2012). It follows that these individual differences and personality traits might moderate the impact of psychological distance on value perceptions. We outline two important potential moderators concerning customer characteristics in value creation: the extent to which a customer is seeking authority and the emotionality of the service. The propositions outlined in this paper therefore make allowances for differences between individuals as well as between service contexts whilst offering guiding principles through which the service interaction can be understood in relation to customers' psychological processes, specifically psychological distance. 


\section{References}

Alford, B.L. and Sherrel, D.L. (1996), "The Role of Affect in Consumer Satisfaction Judgments of Credence-Based Services", Journal of Business Research, 37 71-84.

Babin, B.J. and James, K.W. (2010), "A Brief Retrospective and Introspective on Value", European Business Review, 22 (5) 471-78.

Bar-Anan, Y., Liberman, N., and Trope, Y. (2006). "The association between psychological distance and construal level: Evidence from an implicit association test." Journal of Experimental Psychology-General, 135(4), 609-622.

Bar-Anan, Y., Liberman, N., Trope, Y., and Algom, D. (2007). “Automatic processing of psychological distance: evidence from a Stroop task". Journal of Experimental Psychology-General, 136(4), 610-622.

Bendapudi, N. and Leone, R.P. (2003). Psychological implications of customer participation in co-production. Journal of Marketing, 67 (1) 14-28.

Bitner, M.J., Faranda, W.T., Hubbert, A.R. and Zeithaml, V.A. (1997), “Customer contributions and roles in service delivery," International Journal of Service Industry Management, 8 (3) 193-205.

Breidbach, C. F., Kolb, D. G., \& Srinivasan, A. (2013). „Connectivity in Service Systems: Does Technology-Enablement Impact the Ability of a Service System to Co-Create Value?" Journal of Service Research, 16, 428-441.

Carù, A. and Cova, B. (2003). "Revisiting Consumption Experience : A More Humble but Complete View of the Concept", Marketing Theory, 3 (2) 267-286.

Citera, M., Beauregard, R., and Mitsuya, T. (2005). "An Experimental Study of Credibility in E-negotiations". Psychology and Marketing, 22(2), 163-179.

Crosby, L.A., Evans, K.R. and Cowles, D. (1990), "Relationship Quality in Services Selling: An Interpersonal Influence Perspective", Journal of Marketing, 54 (3) 68-81.

Cyr, D., Hassanein, K., Head, M., \& Ivanov, A. (2007). The role of social presence in establishing loyalty in e-Service environments. Interacting with Computers, 19, 43-56

Danziger, S., Montal, R., and Barkan, R. (2012).” Idealistic advice and pragmatic choice: a psychological distance account". Journal of Personality and Social Psychology, 102(6), 1105-1117.

Dasu, S., \& Chase, R., B. (2013). The Customer Service Solution. New York: McGraw-Hill Education.

Davis, J. I., Gross, J. J., \& Ochsner, K. N. (2011). "Psychological Distance and Emotional Experience: What You See Is What You Get”. Emotion, 11, 438-444. 
Dhar, R., and Kim, E., Y. (2007). Seeing the Forest or the Trees: Implications of Construal Level Theory for Consumer Choice. Journal of Consumer Psychology, 17 (2), 96-100.

Fujita, K., Henderson, M. D., Eng, J., Trope, Y., and Liberman, N. (2006). "Spatial distance and mental construal of social events". Psychological Science, 17(4), 278-282.

Giacomantonio, M., De Dreu, C. K., and Mannetti, L. (2010). "Now you see it, now you don't: interests, issues, and psychological distance in integrative negotiation". Journal of Personality and Social Psychology, 98(5), 761-774.

Goodman, J., K. , and Malkoc, S., A. (2012) "Choosing Here and Now versus There and Later: The Moderating Role of Psychological Distance on Assortment Size Preferences". Journal of Consumer Research, 39, 751-768.

Grönroos, C. (1978), "A service-orientated approach to the marketing of services", European Journal of Marketing, 12 (8), 588-601.

Grönroos, C., (1990), "Relationship Approach to the Marketing Function in Service Contexts: The Marketing and Organizational Behavior Interface", Journal of Business Research, 20 (1) $3-12$

Grönroos, C. (1994), "From Marketing Mix to Relationship Marketing: Towards a Paradigm Shift in Marketing", Management Decision, 37 (2) 4-20.

Grönroos, C. (2008), "Service Logic Revisited: Who Creates Value? and Who Co-Creates?" European Business Review, 20 298-314.

Grönroos, C. (2011) 'Value creation in service logic: A critical analysis', Marketing Theory, 11 (3) 279-301.

Grönroos, C. (2012) 'Conceptualising Value Co-creation: A Journey to the 1970s and Back to the Future', Journal of Marketing Management, 28(13-14) 1520-34.

Grönroos, C., Heinonen, F., Isoniemi, K., and Lindholm, M. (2000), "The NetOffer model: a case example from the virtual marketspace", Management Decision, 38 (4) 243-252.

Grönroos, C. and Voima, P. (2013), "Critical service logic: making sense of value creation and co-creation", Journal of the Academy of Marketing Science, 41 (2) 133-150.

Gummerus, J. (2013), "Value Creation Processes and Value Outcomes in Marketing Theory Strangers Or Siblings?" Marketing Theory, 13 19-46.

Helkkula, A. and Kelleher, C. (2010), "Circularity of customer service experience and customer perceived value", Journal of Customer Behavior, 9 (1) 37-53.

Helkkula, A., Kelleher, C. and Pihlström, M. (2012), "Characterizing value as an experience: implications for service researchers and managers", Journal of Service Research, 15 (1) $59-75$. 
Henderson, M., D, Trope, Y., and Carnevale, P., J. (2006). "Negotiation From a Near and Distant Time Perspective”. Journal of Personality and Social Psychology, 91(4), 712-729.

Higgins, E. T. (2000). "Making a good decision: Value from fit”. American Psychologist (November), 1217-1229.

Higgins, E. T. (2006). "Value from hedonic experience and engagement." Psychological Review, 113, 439-460.

Higgins, E. T., \& Scholer, A. A. (2009). "Engaging the consumer: The science and art of the value creation process". Journal of Consumer Psychology, 19, 100-114.

Holbrook, M. B. (2005). “Customer value and autoethnography: subjective personal introspection and the meanings of a photograph collection". Journal of Business Research, $58,45-61$.

Holbrook, M., B., and Hirschman, E, C. (1982). The Experiential Aspects of Consumption: Consumer Fantasies, Feelings, and Fun. Journal of Consumer Research, 9 (2), 132-140.

Holmqvist, J. and Grönroos, C. (2012), "How does language matter for services? Challenges and propositions for service research," Journal of Service Research, 15 (4), 430-442.

Jin, L., and He, Y. (2012) "Designing Service Guarantees With Construal Fit: Effects of Temporal Distance on Consumer Responses to Service Guarantees". Journal of Service Research, 16(2), 202-215.

Karababa, E. and Kjeldgaard, D. (2013) "Value in Marketing: Toward sociocultural perspectives", Marketing Theory doi: 10.1177/1470593113500385.

Kolb, D. G. (2008). "Exploring the metaphor of connectivity: Attributes, dimensions and duality”. Organization Studies, 29, 127-144.

Laroche, M., McDougall, G.H.G., Bergeron, J., and Yang, Z. (2005), “Exploring how Intangibility Affects Perceived Risk," Journal of Service Research, 6 (4), 373-389.

Lee, A. Y., Keller, P. A., \& Sternthal, B. (2010). „Value from Regulatory Construal Fit: The Persuasive Impact of Fit between Consumer Goals and Message Concreteness." Journal of Consumer Research, 36, 735-747.

Liberman, N., Sagristano, M. D., and Trope, Y. (2002). "The effect of temporal distance on level of mental construal". Journal of Experimental Social Psychology, 38(6), 523-534.

Liberman, N., Trope, Y., and Stephan, E. (2007). "Psychological distance ». In A. W. Kruglanski \& E. T. Higgins (Eds.), Social psychology: Handbook of basic principles (Vol. 2, pp. 353-383). New York: Guilford Press. 
Liberman, N., Trope, Y., McCrea, S. M., and Sherman, S. J. (2007). "The effect of level of construal on the temporal distance of activity enactment". Journal of Experimental Social Psychology, 43(1), 143-149.

Lii, Y. S., Chien, C. S., Pant, A., \& Lee, M. (2013). The challenges of long-distance relationships: the effects of psychological distance between service provider and consumer on the efforts to recover from service failure. Journal of Applied Social Psychology, 43(6), 1121-1135.

Lovelock, C.H. (1983), "Classifying Services to Gain Strategic Marketing Insights", Journal of Marketing, 47 (3) 9-20.

Maglio, P. and Spohrer, J. (2008). "Fundamentals of Service Science", Journal of the Academy of Marketing Science, 38, 18-20.

Makarem, S. C., Mudambi, S. M., \& Podoshen, J. S. (2009). "Satisfaction in technologyenabled service encounters", Journal of Services Marketing, 23, 134-143.

Miao, L. and Mattila, A.S. (2013). "The Impact of Other Customers on Customer Experience: A Psychological Distance Perspective", Journal of Hospitality and Tourism Research, 37 (1) $77-99$.

Nenkov, G., Y. (2012). "It's all in the mindset: Effects of varying psychological distance in persuasive messages". Marketing Letters, 23(3), 615-628.

Nordin, F. and Kowalkowski, C. (2010), "Solutions offerings: A critical review and reconceptualisation", Journal of Service Management, 21(4), 441-459.

Normann, R. (2000), Service Management. Strategy and leadership in service business, $3^{\text {rd }}$ ed. Chichester: John Wiley \& Co.

Ng, I. C. L., Nudurupati, S. S., and Tasker, P. (2010). Value co-creation in the delivery of outcome-based contracts for business-to business service. AIM working paper series, No. 77 (May). Available at: http://www.aimresearch.org/index.php?page0wp-no-77

Parasuraman, A., Zeithaml, V.A. and Berry, L. L. (1988), "SERVQUAL: A multiple-item scale for measuring consumer perceptions of service quality", Journal of Retailing, 64 (1) $12-40$.

Payne, A., Storbacka, K. and Frow, P. (2008), "Managing the Co-Creation of Value", Journal of the Academy of Marketing Science, 36 (1) 83-96.

Peñaloza, L. and Mish, J. (2011), "The Nature and Processes of Market Co-creation in Triple Bottom Line Firms: Leveraging Insights from Consumer Culture Theory and Service Dominant Logic", Marketing Theory, 11(9) 9-34. 
Rim, S., Uleman, J. S., \& Trope, Y. (2009). "Spontaneous trait inference and construal level theory: Psychological distance increases nonconscious trait thinking." Journal of Experimental Social Psychology, 45(5), 1088-1097.

Rosch, E. (1975). “Cognitive Representations of Semantic Categories”. Journal of Experimental Psychology-General, 104(3), 192-233.

Sheth, J.N. and Uslay, C. (2007), "Implications of the Revised Definition of Marketing: From Exchange to Value Creation", Journal of Public Policy and Marketing, 26 (2) 302-307.

Smith, P. K., and Trope, Y. (2006). "You focus on the forest when you're in charge of the trees: power priming and abstract information processing". Journal of Personality and Social Psychology, 90(4), 578-596.

Sousa, C. M. P., and Bradley, F. (2006). "Cultural distance and psychic distance: Two peas in a pod?" Journal of International Marketing, 14(1), 49-70.

Spohrer, J., Maglio, P. P., Bailey, J., \& Gruhl, D. (2007). "Steps toward a science of service systems". Computer, 40,71-77

Stephan, E., Liberman, N., and Trope, Y. (2010). "Politeness and psychological distance: a construal level perspective". Journal of Personality and Social Psychology, 98(2), 268280.

Surprenant, C.F. and Solomon, M.R. (1987), "Predictability and personalization in the service encounter". Journal of Marketing, 51 (2) 73-80.

Thomas, M., and Tsai, C., I. (2012). "Psychological Distance and Subjective Experience: How Distancing Reduces the Feeling of Difficulty". Journal of Consumer Research, 39(2), 324-340.

Trapnell, P.D., Campbell, J.D., (1999). Private self-consciousness and the five-factor model of personality: distinguishing rumination from reflection. Journal of Personality and Social Psychology. 76, 284-304.

Trope, Y., and Liberman, N. (2000). “Temporal construal and time-dependent changes in preference.” Journal of Personality and Social Psychology, 79 (6), 876-889.

Trope, Y., and Liberman, N. (2003). “Temporal construal”. Psychological Review, 110, 403421.

Trope, Y., and Liberman, N. (2010). "Construal-level theory of psychological distance". Psychological Review, 117(2), 440-463.

Trope, Y., Liberman, N., and Wakslak, C. (2007). "Construal levels and psychological distance: Effects on representation, prediction, evaluation, and behaviour". Journal of Consumer Psychology, 17(2), 83-95. 
Vallacher, R. R., and Wegner, D. M. (1987). „What Do People Think They're Doing - Action Identification and Human-Behavior." Psychological Review, 94 (1), 3-15.

Van Boven, L., Kane, J., McGraw, A. P., and Dale, J. (2010). "Feeling close: emotional intensity reduces perceived psychological distance". Journal of Personality and Social Psychology, 98(6), 872-885.

Van Vaerenbergh, Y. and Holmqvist, J. (2013), "Speak my language if you want my money: service language's influence on consumer tipping behavior", European Journal of Marketing, 47 (8) 1276-1292.

Vargo, Stephen L. and Robert F. Lusch (2004), "Evolving to a New Dominant Logic for Marketing," Journal of Marketing, 68 1-17.

Vargo, S.L. and Lusch, R.F. (2008) ‘Service-Dominant Logic: Continuing the Evolution’, Journal of the Academy of Marketing Science, 36(1): 1-10.

Wakslak, C., and Trope, Y. (2009). "The effect of construal level on subjective probability estimates". Psychological Science, 20(1), 52-58.

Wakslak, C. J., Trope, Y., Liberman, N., \& Alony, R. (2006). "Seeing the forest when entry is unlikely: Probability and the mental representation of events." Journal of Experimental Psychology-General, 135(4), 641-653.

Woodruff, R.B. (1997). "Customer Value: The next source for competitive advantage". Journal of the Academy of Marketing Science, 25 (2) 139-153.

Zeithaml, V.A., Berry, L.L. and Parasuraman, A. (1996), “The Behavioral Consequences of Service Quality," Journal of Marketing, 60 (2), 31-46.

Zeithaml, V.A. and Bitner, M.J. (2000), Services Marketing: Integrating Customer Focus across the Firms, 2nd ed. New York: McGraw-Hill.

Zhao, M., and Xie, J. (2011). "Effects of Social and Temporal Distance on Consumers' Responses to Peer Recommendations". Journal of Marketing Research, 48(3), 486-496. 